\title{
Comparison of the Extracorporeal Treatments in Poisoning (EXTRIP) and Paris Criteria for Lithium Poisoned Patients
}

\author{
Philip DiSalvo ${ }^{1}$, Emma Furlano ${ }^{1},{\text { Mark } \mathrm{Su}^{2} \text {, Sophie Gosselin }}^{3}$, and Robert Hoffman ${ }^{1}$ \\ ${ }^{1}$ NYU Grossman School of Medicine \\ ${ }^{2}$ New York City Poison Control Center \\ ${ }^{3}$ Hopital Charles-Lemoyne
}

October 27, 2020

\begin{abstract}
Aim: Two recommendations for hemodialysis in lithium poisoning, one from the Extracorporeal TReatments in Poisoning (EXTRIP) workgroup and a single center retrospective one (Paris), differ. We compared outcomes in lithium poisoning based on these criteria with a primary outcome of worsening neurological symptoms in patients where EXTRIP and Paris criteria were discordant. Methods: Poison center data were queried for lithium poisoned patients for whom hemodialysis was either recommended or performed. Patients were categorized according to EXTRIP and Paris criteria and excluded if the peak lithium concentration was $<1.2 \mathrm{mmol} / \mathrm{L}$ or if neurological follow-up was unavailable. Comparative analyses were only performed when both criteria could be assessed. Results: 219 patients were analyzed. Paris criteria were applied in 70 and EXTRIP criteria in 178. 42 patients were excluded because Paris criteria could not be applied. When Paris and EXTRIP both supported hemodialysis, 50/57 (88\%) of patients who received hemodialysis improved, as did all 3 who did not receive hemodialysis. When Paris and EXTRIP opposed hemodialysis, all non-dialyzed patients did well. Among the 86 patients for whom EXTRIP supported hemodialysis but Paris did not, $4 / 19$ (21\%) patients not dialyzed deteriorated $(\mathrm{p}=0.02 ; \mathrm{OR}=8.7,95 \% \mathrm{CI}=1.5-51.8)$, one of whom died. All 8 patients for whom Paris criteria supported hemodialysis but EXTRIP did not were dialyzed and improved. Conclusion: When the EXTRIP and Paris criteria are discordant, EXTRIP criteria outperforms the Paris criteria at identifying potentially ill patients who might benefit from hemodialysis.
\end{abstract}

Comparison of the Extracorporeal Treatments in Poisoning (EXTRIP) and Paris Criteria for Lithium Poisoned Patients

${ }^{1}$ Philip C DiSalvo, ${ }^{1}$ Emma Furlano, ${ }^{1,2}$ Mark K Su, ${ }^{3}$ Sophie Gosselin, ${ }^{1}$ Robert S. Hoffman

\section{Author Affiliations}

1. Division of Medical Toxicology, Ronald O. Perelman Department of Emergency Medicine, NYU Grossman School of Medicine, NY, NY, USA

2. New York City Poison Control Center, NY, NY, USA

3. Centre Intégré de Santé et de Services Sociaux (CISSS) Montérégie-Centre Emergency Department, Hôpital Charles-Lemoyne, Greenfield Park, QC, the Department of Emergency Medicine, McGill University, Montreal, and Centre Antipoison du Québec, Canada

Author for Correspondence

Philip DiSalvo, MD 
455 First Avenue

Room 123

New York, NY, 10016

Phone: 202-251-5964

Email: disalvo@gmail.com

All authors have made substantial contributions to conception and design, acquisition of data, or analysis and interpretation of data; have been involved in drafting the manuscript or revising it critically for important intellectual content; and give final approval of the version to be published.

The authors confirm that the PI for this paper is Dr. Robert S. Hoffman. No interventions were performed with human subjects/patients nor were substances administered to human subjects/patients. This study was deemed exempt from comprehensive review by the NYC DOHMH IRB.

None of the authors have any financial conflicts of interest to declare. Drs. Hoffman and Gosselin served on EXTRIP and participated in the development of EXTRIP's lithium guidelines.

The data that support the findings of this study are available on request from the corresponding author. The data are not publicly available due to privacy/ethical restrictions.

\section{Running head: Li Poisoning: EXTRIP vs. Paris Criteria}

Key words: Lithium, Poisoning, Extracorporeal treatment, Hemodialysis Word count: 2236

Table count: 6

\section{What is already known about this subject:}

The indications for hemodialysis in lithium poisoned patients are not established based on randomized controlled trials. The EXTRIP and Paris recommendations provide clinically useful guidance but differ in some aspects. Neither have been externally validated.

What this study adds:

- When Paris and EXTRIP criteria both support hemodialysis, outcomes were similar in dialyzed patients

- When Paris and EXTRIP criteria both oppose hemodialysis, outcomes were similar in non-dialyzed patients

- When hemodialysis was supported by EXTRIP criteria but not Paris criteria and patients were not dialyzed, outcomeswere worse, including one death

\section{ABSTRACT}

\section{Aim:}

Two recommendations for hemodialysis in lithium poisoning, one from the Extracorporeal TReatments in Poisoning (EXTRIP) workgroup and a single center retrospective one (Paris) differ. We compared outcomes in lithium poisoning based on these criteria with a primary outcome of worsening neurological symptoms in patients where EXTRIP and Paris criteria were discordant. 


\section{Methods:}

Poison center data were queried for lithium poisoned patients for whom hemodialysis was either recommended or performed. Patients were categorized according to EXTRIP and Paris criteria and excluded if the peak lithium concentration was $<1.2 \mathrm{mmol} / \mathrm{L}$ or if neurological follow-up was unavailable. Comparative analyses were only performed when both criteria could be assessed.

\section{Results:}

219 patients were analyzed. Paris criteria were applied in 70 and EXTRIP criteria in 178. 42 patients were excluded because Paris criteria could not be applied. When Paris and EXTRIP both supported hemodialysis, $50 / 57$ (88\%) of patients who received hemodialysis improved, as did all 3 who did not receive hemodialysis. When Paris and EXTRIP opposed hemodialysis, all non-dialyzed patients did well. Among the 86 patients for whom EXTRIP supported hemodialysis but Paris did not, 4/19 (21\%) patients not dialyzed deteriorated $(\mathrm{p}=0.02 ; \mathrm{OR}=8.7,95 \% \mathrm{CI}=1.5-51.8)$, one of whom died. All 8 patients for whom Paris criteria supported hemodialysis but EXTRIP did not were dialyzed and improved.

\section{Conclusion:}

When the EXTRIP and Paris criteria are discordant, EXTRIP criteria outperforms the Paris criteria at identifying potentially ill patients who might benefit from hemodialysis.

\section{INTRODUCTION}

Lithium first saw clinical use as a means to reduce uric acid concentrations in patients with gout. The moodaltering effects of lithium led internist Alfred Baring Garrod to erroneously infer the presence of "brain gout" in 1859. In 1871, William Hammond first described the use of Lithium for mania, but widespread adoption did not follow until the mid-20th century.[1]

Despite having decades of proof as an effective treatment for bipolar disorders, lithium use is hampered by a narrow therapeutic index, and toxicity is common. The manifestations of toxicity vary based on acuity of exposure, with gastrointestinal manifestations predominating in acute overdose and neurologic manifestation in chronic accumulation, either by over medication or reduced elimination. Following lithium toxicity, some patients develop prolonged or permanent neurological sequelae, known as the Syndrome of Irreversible Lithium-Effectuated Neurotoxicity (SILENT), which spans a spectrum of neurological symptoms from mild tremors to debilitating cognitive and motor impairments.[2] While the risks for the development of long-term sequelae are not well characterized, there is an association between the duration of elevated serum lithium concentrations (reflecting a high CNS lithium concentration) and an increased likelihood of serious or prolonged symptoms. [3] It follows that expeditious removal of lithium from the body may limit long-term toxicity.

Lithium is well suited for removal by hemodialysis. It is a small molecule, with minimal protein binding and a volume of distribution of 0.7-0.9 L/kg.[4] While it is undisputed that hemodialysis removes lithium, the clinical efficacy of hemodialysis has not been definitively established by well-designed randomized controlled trials. As such, identifying patients likely to benefit from hemodialysis is challenging. The Extracorporeal Treatments in Poisoning Workgroup published a systematic review of the literature in 2015 and established expert consensus guidelines on the use of hemodialysis in lithium poisoning. Despite expert consensus, all suggestions and recommendations were based on very low levels of evidence.[5] The EXTRIP guidelines have never been externally validated.

Seeking to hone these guidelines with the aim of reducing potentially unnecessary treatments, a retrospective analysis of 128 ICU patients with lithium toxicity identified a lithium concentration [?] $5.2 \mathrm{mmol} / \mathrm{L}$ or creatinine [?]200 $\mu \mathrm{mol} / \mathrm{L}$ as indicators for hemodialysis. [6] On a subsequent analysis, these "Paris" criteria were 
applied retrospectively to the same cohort, and compared to EXTRIP criteria. For each set of criteria, neurological status at ICU discharge was compared between patients who met the criteria and underwent ECTR and those who met the criteria but did not undergo ECTR.[7] The authors conclude that the application of Paris criteria led to a statistical difference in outcome in the primary analysis, and that application of the EXTRIP criteria leads to ECTR in more patients than is necessary, although they acknowledge modifications to the published EXTRIP criteria used in their analysis and the inherent circular nature of validation of the Paris criteria using the derivation cohort.

To our knowledge, neither EXTRIP nor Paris criteria have been independently validated or compared. In this study we applied both EXTRIP and Paris criteria retrospectively to a cohort of patients in a poison center database to determine if differences in neurologic outcomes were significant in cases in which criteria were discordant.

\section{METHODS}

The New York City Poison Control Center provides toxicology consultation services to a population of approximately 12 million people. It maintains an electronic database of all cases dating back to Jan 1, 2000. Cases are coded for basic demographics, acuity, clinical effects, the treatments recommended and provided, and medical outcome, all using standardized fields in Toxicall (Computer Automated Systems, Aurora Colorado) and in accordance with case definitions created by the American Association of Poison Control Centers. Case records also include a free-text narrative that describes the clinical course and additional diagnostic studies. By routine, these narratives are updated until the patient's clinical course plateaus, the patient is discharged, or the patient is transferred to psychiatric care. We performed a Structured Query Language (SQL) search for all cases of human lithium poisoning in which hemodialysis was coded as either recommended and/or performed. It is important to note that if the poison center was consulted regarding the indications for hemodialysis, the decision was made by the on-call consultant. After 2015, the EXTRIP criteria may or may not have been applied by the individual consultants but were never formally adopted as a poison center protocol.

The study protocol was preliminarily reviewed by our IRB and deemed exempt from comprehensive review due to absence of potential harm to research subjects. The database was searched from its inception $(1 / 1 / 2000)$ through $5 / 24 / 20$. Cases were then manually reviewed by one of two authors (PD, EF), and data were extracted using a predetermined form. Data were collected and managed using REDCap electronic data capture tools. [8],[9] The data collection form was piloted and reviewed, coding rules for subjective variables were agreed upon by abstractors a priori. Abstractors were not blinded to study objectives. Cases met inclusion criteria if there was a documented $\mathrm{Li}$ concentration $>1.2 \mathrm{mmol} / \mathrm{L}$ and new neurological symptoms were recorded.

For each case record, the following information was collected: date; age; sex; initial and peak lithium concentrations $([\mathrm{Li}])$ if multiple concentrations were provided; acuity; coingestions; presence or absence of neurological symptoms, dysrhythmias, seizures, coma, or confusion; creatinine if provided; whether there was a either a documented [Li] $>1 \mathrm{mmol} / \mathrm{L}$ after 36 hours or a documented [Li] $<1 \mathrm{mmol} / \mathrm{L}$ before 36 hours; hemodialysis recommendations and additional treatments or GI contamination including IV fluids, activated charcoal, and whole bowel irrigation; whether or not of hemodialysis was performed; and medical outcome, graded as resolved, improved, unchanged, worsened, or not reassessed. For cases in which the coded data conflicted with the narrative account, the narrative account was taken as authoritative.

Cases were then evaluated to determine if they met criteria established by the EXTRIP workgroup sufficient to "suggest" or "recommend" hemodialysis and whether or not they met Paris criteria (Tables 1). Calculations of the eGFR by the CKD-EPI formula were not adjusted for race, as race is not routinely collected in our database. Predicted lithium concentration at 36 hours after presentation was determined to be a subjective variable not coded or routinely collected in our database, and thus was not used to make determinations of EXTRIP criteria applicability.

Statistical Analysis 
Cases were included in comparative analyses only when data were sufficient to assess both Paris and EXTRIP criteria. Direct comparisons were performed by Fisher's exact test. Odds ratios were calculated for risk of clinical deterioration (death or worsening neurological status).

\section{RESULTS}

From over 2,000,000 cases in the database, 3541 lithium cases originated from health care facilities, 347 had hemodialysis recommended or performed, and 298 recorded both a supratherapeutic lithium concentration and new neurological symptoms. Following exclusion for incomplete data, 219 patients were analyzed.(Table 2) The Paris criteria could be applied to 70 patients, while one or both EXTRIP criteria could be applied to 178 patients (78 "recommended"; 146 "suggested"). Forty-two patients were excluded from the comparison because data were insufficient to determine whether Paris criteria could be applied.

Seventy patients met PARIS criteria for hemodialysis. (Table 3) Three deteriorations (all of whom died) occurred among the 65 patients who had hemodialysis. No deteriorations occurred in the 5 patients who did not have hemodialysis. Statistical analysis was not performed because no events occurred in one cell. One-hundred and seven patients did not meet Paris criteria for hemodialysis. Deteriorations occurred in $2 / 83$ patients $(2.4 \%)$ dialyzed as opposed to $4 / 24$ patients $(16.6 \%)$ not dialyzed $(\mathrm{p}=0.022)$ The odds ratio of deterioration for patients who did not meet PARIS criteria for hemodialysis and were not dialyzed was 8.1 (95\% CI 1.4-47.4).

Table 3 shows the data, analysis and comparisons for patients who met the EXTRIP suggests criteria. As noted above, many statistical comparisons were not possible because of zero events occurring in at least one cell. Only two analyses reached statistical significance. Among the 107 patients who did not meet the Paris criteria for hemodialysis, 83 underwent the procedure. Neurological deterioration was more likely in the remaining 24 patients who were not dialyzed ( $\mathrm{p}=0.22$; OR 8.10(95\% CI 1.39 - 47.39). For 81 patients outcomes could be compared when EXTRIP criteria were met and PARIS criteria were not. Clinical deterioration was more likely in these patients when they did not undergo hemodialysis $(\mathrm{p}=0.01$, OR 8.67 $95 \%$ CI: $1.42-52.94)$. When both criteria were met the majority of patients were dialyzed and there were no deteriorations. Similarly, when both criteria were not met, the majority of patients were dialyzed and there were no deteriorations.

Table 4 shows the data and analysis and comparisons for patients who met the EXTRIP recommend criteria. As noted above, many comparisons were not possible because of zero events occurring in at least one cell. The comparison between EXTRIP recommends and PARIS did not reach statistical significance.

There were 181 patients who met either the recommended or suggested EXTRIP criteria for hemodialysis. Their analysis is summarized in table 5 . Four of the $26(15.4 \%)$ who did not have hemodialysis deteriorated and one patient died as opposed to the 151 patients who underwent hemodialysis among whom 5 deteriorated $(3.3 \%)$ and 3 died $(\mathrm{p}=0.031)$. The odd ratio for deterioration in the patients not dialyzed was 5.1 (95\% CI 1.3-20.3). In 41 patients EXTRIP neither recommended nor suggested hemodialysis. All patients did well including 5/41 who did not receive hemodialysis. Statistical analysis was not performed because no events occurred in one cell. For 62 patients both the PARIS criteria and at least one of the EXTRIP criteria for hemodialysis were met. The only three deteriorations were among the 57 patients who underwent hemodialysis. Statistical analysis was not performed because no events occurred in one cell. There were 21 patients who fulfilled neither criteria for hemodialysis. There were no deteriorations in this group, including the five patients who did not receive hemodialysis. Statistical analysis was not performed because no events occurred in one cell. There were 86 patients who met at least one of the two EXTRIP criteria for hemodialysis but did not meet the Paris criteria. Hemodialysis was performed in 67 patients two of whom (3.0\%) deteriorated. In contrast, among patients not dialyzed 4/19 (21.1\%) deteriorated, one of whom died $(\mathrm{p}=0.019)$. The odd ratio for deterioration if dialysis was not performed when EXTRIP was in favor of hemodialysis and PARIS was not was 8.7 (95\% CI 1.5-51.8). Table 6 provides a more detailed description of these four patients. Finally, there were 8 patients for whom PARIS was in favor of hemodialysis but neither of the two EXTRIP criteria were met. All 8 patients underwent hemodialysis and there were no 
deteriorations. Statistical analysis was not performed because no events occurred in one cell.

\section{DISCUSSION}

In this single center retrospective analysis, in whom hemodialysis was performed or recommended by our PCC, when the EXTRIP and Paris criteria are both in favor of hemodialysis, dialyzed patients generally had favorable outcomes. When the two criteria are against hemodialysis, non-dialyzed patients also had favorable outcomes. As reported by its creators, application of the Paris guidelines prompts dialysis in fewer patients overall, but when the criteria were discordant, the EXTRIP criteria outperformed the Paris criteria at identifying potentially ill patients who might benefit from hemodialysis. Of the cases of deterioration not identified by the Paris criteria, two were not identified by the EXTRIP "recommends" criteria, and all four were identified by the EXTRIP "suggests" criteria. EXTRIP criteria were not intended to be merged for comparative analysis, but this comparison is presented here to reflect the merged EXTRIP analysis performed in the original Paris validation study.

Descriptive data are unfortunately limited for these cases. We cannot completely exclude processes unrelated to their lithium toxicity contributing to patients' deterioration. This qualification, however, is equally applicable to all cohorts and reflects the typical quality of data from poison control center databases. Furthermore, poison center data can be limited by completeness and accuracy for coded clinical effects and treatments.[10],[11] There may have been variability between original PCC coders for clinical effects such as "confusion," "altered mental status," and "other-miscellaneous." Narrative accounts can be selective in their inclusion/exclusion of relevant data and can terminate in many cases before the outcome of interest is determined in a subsequent retrospective study. Long term outcomes such as SILENT cannot be extrapolated from poison center cases, for example, as routine follow up on the order of months or years is seldom performed.

Additionally, our cohort possibly suffers from two sources of selection bias. There may have been cases in which EXTRIP or Paris criteria were met, but dialysis was neither recommended nor performed. These cases would not have been identified by our search criteria but were unlikely to be significantly ill since most sources prior to EXTRIP suggest more liberal indications for hemodialysis. Additionally, we only reviewed cases reported to one regional metropolitan poison center in the United States. Since poison center reporting is largely voluntary, we may have missed cases in our catchment area not reported to our center.[12]

\section{Conclusion}

In this retrospective data set, application of the Paris guidelines would have resulted in fewer overall cases of hemodialysis for lithium poisoned patients, but would have failed to identify a statistically significant number of patients who may have benefited from expedited extracorporeal drug removal. While the EXTRIP criteria results in an increase in the use of hemodialysis, overall patient outcomes were improved, and fewer patients deteriorated. A prospective study is needed to more conclusively determine the relative performance characteristics of both EXTRIP and Paris criteria.

Table 1: The EXTRIP and Paris Criteria for Hemodialysis and Lithium Poisoning

EXTRIP

Hemodialysis Recommended Li concentration $>4.0 \mathrm{mmol} / \mathrm{L}$ with impaired kidney function eGFR of $>45 \mathrm{~mL} / \mathrm{min}$ per 1.73 Hemodialysis Suggested Li concentration $>5.0 \mathrm{mmol} / \mathrm{L}$ Confusion is present Expected time to obtain $[\mathrm{Li}]<1.0 \mathrm{mmol} / \mathrm{L}$ is

Table 2: Patient Characteristics

\begin{tabular}{llllll}
\hline & Total & EXTRIP & EXTRIP & Either EXTRIP & Paris \\
& & Suggests & Recommends & & Recommends \\
$\mathrm{n}$ & 219 & 146 & 78 & 178 & 70 \\
$\begin{array}{l}\text { Mean age } \\
\text { (years) }\end{array}$ & 47 & 50 & 43 & 48 & 46 \\
& & & &
\end{tabular}




\begin{tabular}{lccccc} 
Sex $(\%$ female $)$ & 60.7 & 59.6 & 57.7 & 61.2 & 52.9 \\
$\begin{array}{l}\text { Mean Lithium } \\
\text { Concentration }\end{array}$ & 3.59 & 3.82 & 4.31 & 3.71 & 4.51 \\
$\begin{array}{l}\text { (mmol/L) } \\
\text { Mean }\end{array}$ & & & & & 337 \\
$\begin{array}{l}\text { Creatinine } \\
(\mu \mathrm{mol} / \mathrm{L})\end{array}$ & 202 & 216 & 205 & 211 & \\
\hline
\end{tabular}

${ }^{a}$ one or more cases did not include an exact value for the variable, and were therefore excluded from average calculations

Table 3: Comparison of Outcomes - EXTRIP Suggests

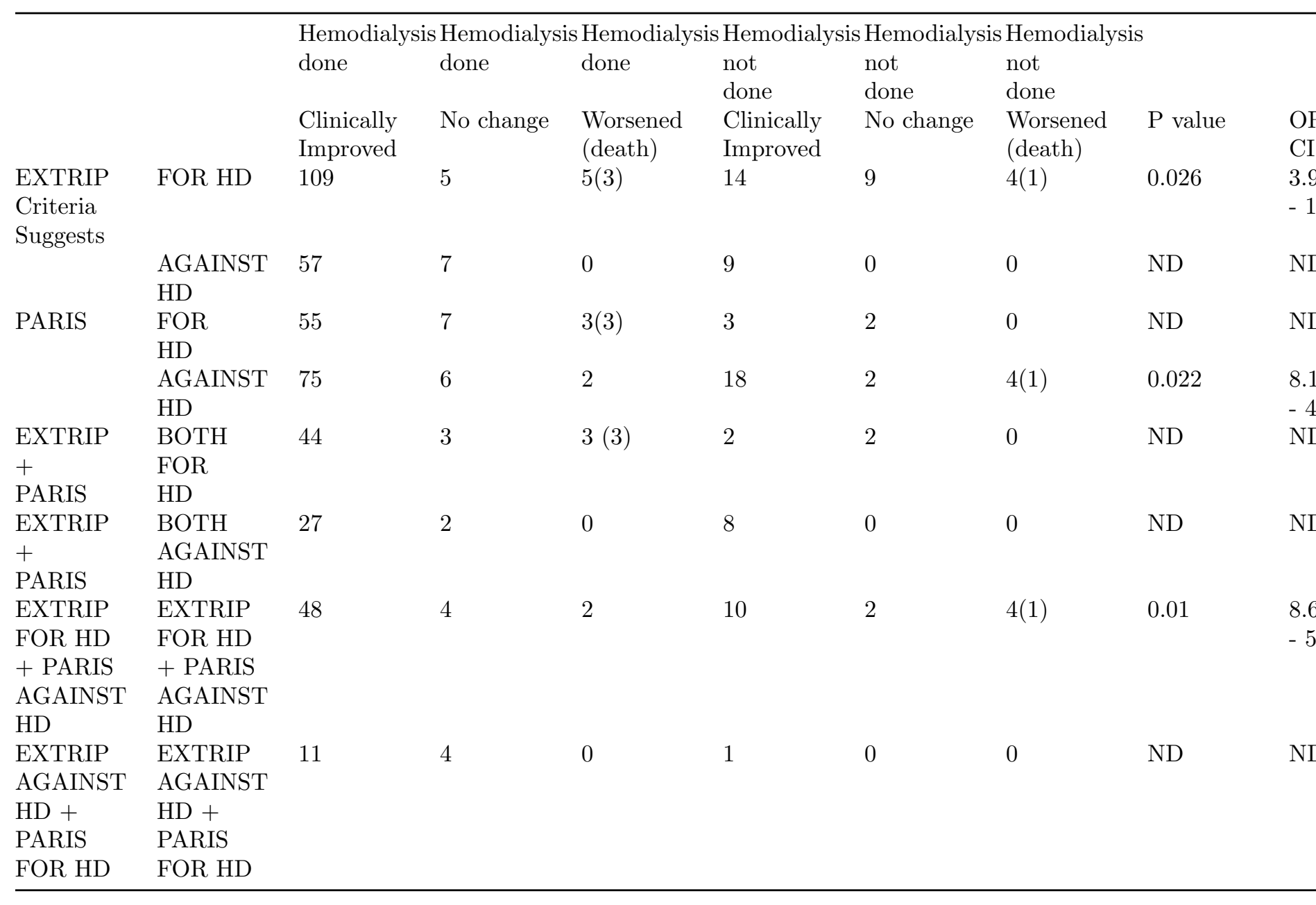

$\mathrm{ND}=$ no comparison done because of empty cells; $\mathrm{HD}=$ hemodialysis

Table 4: Comparison of Outcomes - EXTRIP Recommends

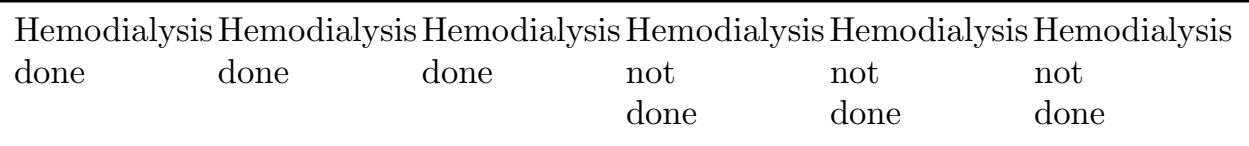




\begin{tabular}{|c|c|c|c|c|c|c|c|c|}
\hline & & $\begin{array}{l}\text { Clinically } \\
\text { Improved }\end{array}$ & No change & $\begin{array}{l}\text { Worsened } \\
\text { (death) }\end{array}$ & $\begin{array}{l}\text { Clinically } \\
\text { Improved }\end{array}$ & No change & $\begin{array}{l}\text { Worsened } \\
\text { (death) }\end{array}$ & $\mathrm{P}$ value \\
\hline EXTRIP & FOR HD & 56 & 6 & $5(3)$ & 8 & 1 & $2(1)$ & 0.13 \\
\hline \multicolumn{9}{|c|}{$\begin{array}{l}\text { Criteria } \\
\text { Recommend }\end{array}$} \\
\hline & $\begin{array}{l}\text { AGAINST } \\
\text { HD }\end{array}$ & 103 & 9 & 0 & 15 & 4 & 2 & ND \\
\hline \multirow[t]{2}{*}{ PARIS } & $\begin{array}{l}\text { FOR } \\
\text { HD }\end{array}$ & 55 & 7 & $3(3)$ & 3 & 2 & 0 & ND \\
\hline & $\begin{array}{l}\text { AGAINST } \\
\text { HD }\end{array}$ & 75 & 6 & 2 & 18 & 2 & $4(1)$ & 0.022 \\
\hline EXTRIP & BOTH & 22 & 2 & $3(3)$ & 3 & 1 & 0 & ND \\
\hline+ & FOR & & & & & & & \\
\hline PARIS & $\mathrm{HD}$ & & & & & & & \\
\hline EXTRIP & ВОТН & 50 & 3 & 0 & 14 & 2 & 2 & ND \\
\hline+ & AGAINST & & & & & & & \\
\hline PARIS & $\mathrm{HD}$ & & & & & & & \\
\hline EXTRIP & EXTRIP & 25 & 3 & 4 & 4 & 0 & $2(1)$ & 0.11 \\
\hline FOR HD & FOR HD & & & & & & & \\
\hline + PARIS & + PARIS & & & & & & & \\
\hline AGAINST & AGAINST & & & & & & & \\
\hline HD & HD & & & & & & & \\
\hline EXTRIP & EXTRIP & 29 & 5 & 0 & 0 & 1 & 0 & ND \\
\hline AGAINST & AGAINST & & & & & & & \\
\hline $\mathrm{HD}+$ & $\mathrm{HD}+$ & & & & & & & \\
\hline PARIS & PARIS & & & & & & & \\
\hline FOR HD & FOR HD & & & & & & & \\
\hline
\end{tabular}

$\mathrm{ND}=$ no comparison done because of empty cells; $\mathrm{HD}=$ hemodialysis

Table 5: Comparison of Outcomes - EXTRIP Either Suggests or Recommends

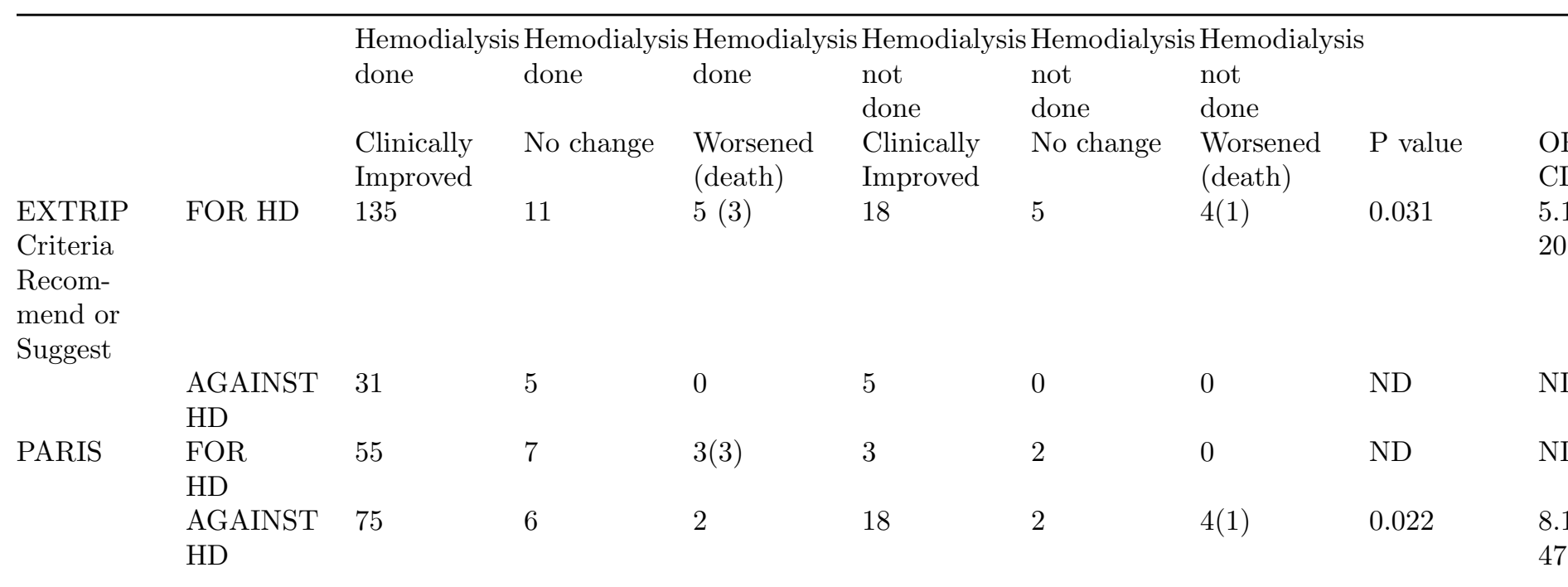




\begin{tabular}{|c|c|c|c|c|c|c|c|c|}
\hline Any & ВОТН & 50 & 4 & $3(3)$ & 3 & 2 & 0 & ND \\
\hline EX- & FOR & & & & & & & \\
\hline $\begin{array}{l}\text { TRIP } \\
+\end{array}$ & HD & & & & & & & \\
\hline \multicolumn{9}{|l|}{ PARIS } \\
\hline Any & ВОтН & 14 & 2 & 0 & 5 & 0 & 0 & ND \\
\hline EX- & AGAINST & & & & & & & \\
\hline TRIP & HD & & & & & & & \\
\hline \multirow{2}{*}{\multicolumn{9}{|c|}{$\begin{array}{l}+ \\
\text { PARIS }\end{array}$}} \\
\hline & & & & & & & & \\
\hline Any & Any & 61 & 4 & 2 & 13 & 2 & $4(1)$ & 0.019 \\
\hline EXTRIP & EXTRIP & & & & & & & \\
\hline FOR HD & FOR HD & & & & & & & \\
\hline + PARIS & + PARIS & & & & & & & \\
\hline AGAINST & AGAINST & & & & & & & \\
\hline $\mathrm{HD}$ & $\mathrm{HD}$ & & & & & & & \\
\hline Any & Any & 5 & 3 & 0 & 0 & 0 & 0 & ND \\
\hline EXTRIP & EXTRIP & & & & & & & \\
\hline AGAINST & AGAINST & & & & & & & \\
\hline $\mathrm{HD}+$ & $\mathrm{HD}+$ & & & & & & & \\
\hline PARIS & PARIS & & & & & & & \\
\hline FOR HD & FOR HD & & & & & & & \\
\hline
\end{tabular}

$\mathrm{ND}=$ no comparison done because of empty cells; HD = hemodialysis

Table 6: Cases of deterioration without hemodialysis when criteria were discordant

\begin{tabular}{|c|c|c|c|c|}
\hline $\begin{array}{l}\text { Patient } \\
\text { presentation }\end{array}$ & $\mathrm{Li}$ & $\mathrm{Cr}$ & EXTRIP Criteria & Outcome \\
\hline $\begin{array}{l}54 \mathrm{M} \text {-bipolar } \\
\text { disease and } \\
\text { hepatitis C } \\
\text {-presented with new } \\
\text { jaundice and } \\
\text { alteration in mental } \\
\text { status }\end{array}$ & $3.3 \mathrm{mmol} / \mathrm{L}$ & $97 \mu \mathrm{mol} / \mathrm{L}$ & Recommend & Death \\
\hline $\begin{array}{l}47 \mathrm{~F} \text {-schizoaffective } \\
\text { disorder -presented } \\
\text { with confusion }\end{array}$ & $4.3 \mathrm{mmol} / \mathrm{L}$ & $88 \mu \mathrm{mol} / \mathrm{L}$ & Suggest & $\begin{array}{l}\text { Deterioration in } \\
\text { mental status }\end{array}$ \\
\hline $\begin{array}{l}58 \mathrm{~F} \text {-bipolar } \\
\text { disorder -presented } \\
\text { with altered mental } \\
\text { status }\end{array}$ & $2.6 \mathrm{mmol} / \mathrm{L}$ & $150 \mu \mathrm{mol} / \mathrm{L}$ & Suggest & $\begin{array}{l}\text { Deterioration in } \\
\text { mental status }\end{array}$ \\
\hline $\begin{array}{l}60 \mathrm{~F} \text {-bipolar } \\
\text { disease -presented } \\
\text { with confusion } \\
\text { tremor, increased } \\
\text { falls }\end{array}$ & $2.85 \mathrm{mmol} / \mathrm{L}$ & $122 \mu \mathrm{mol} / \mathrm{L}$ & Recommend & $\begin{array}{l}\text { Deterioration in } \\
\text { mental status }\end{array}$ \\
\hline
\end{tabular}

\section{Citations}


1. Shorter E. The history of lithium therapy. Bipolar Disord. 2009;11 Suppl 2(Suppl 2):4-9. doi:10.1111/j.1399-5618.2009.00706.x

2. Adityanjee, Munshi KR, Thampy A. The syndrome of irreversible lithium-effectuated neurotoxicity. Clin Neuropharmacol. 2005;28(1):38-49. doi:10.1097/01.wnf.0000150871.52253.b7

3. Hansen HE, Amdisen A. Lithium intoxication. (Report of 23 cases and review of 100 cases from the literature). Q J Med. 1978;47(186):123-144.

4. Timmer RT, Sands JM. Lithium intoxication. J Am Soc Nephrol. 1999;10(3):666-674.

5. Decker BS, Goldfarb DS, Dargan PI, et al. Extracorporeal Treatment for Lithium Poisoning: Systematic Review and Recommendations from the EXTRIP Workgroup. Clin J Am Soc Nephrol. 2015;10(5):875-887. doi:10.2215/CJN.10021014

6. Vodovar D, El Balkhi S, Curis E, Deye N, Mégarbane B. Lithium poisoning in the intensive care unit: predictive factors of severity and indications for extracorporeal toxin removal to improve outcome. Clin Toxicol (Phila). 2016;54(8):615-623. doi:10.1080/15563650.2016.1185110

7. Vodovar D, Beaune S, Langrand J, Vicaut E, Labat L, Mégarbane B. Assessment of Extracorporeal Treatments in Poisoning criteria for the decision of extracorporeal toxin removal in lithium poisoning. Br J Clin Pharmacol. 2020;86(3):560-568. doi:10.1111/bcp.14087

8. Harris PA, Taylor R, Thielke R, Payne J, Gonzalez N, Conde JG. Research electronic data capture (REDCap)-a metadata-driven methodology and workflow process for providing translational research informatics support. J Biomed Inform. 2009;42(2):377-381. doi:10.1016/j.jbi.2008.08.010

9. Harris PA, Taylor R, Minor BL, et al. The REDCap consortium: Building an international community of software platform partners. J Biomed Inform. 2019;95:103208. doi:10.1016/j.jbi.2019.103208

10. Krenzelok EP, Reynolds KM, Dart RC, Green JL. A model to improve the accuracy of US Poison Center data collection. Clin Toxicol (Phila). 2014;52(8):889-896. doi:10.3109/15563650.2014.953169

11. Jaramillo JE, Marchbanks B, Willis B, Forrester MB. Evaluation of completeness of selected poison control center data fields. J Med Syst. 2010;34(4):499-507. doi:10.1007/s10916-009-9263-z

12. Blanc PD, Kearney TE, Olson KR. Underreporting of fatal cases to a regional poison control center. West J Med. 1995;162(6):505-509. 